\title{
Subliminal Priming of Motivation Magnitude
}

\author{
Fabian Steinberg, Otmar Bock, Sebastian Dern \\ Institute of Physiology and Anatomy, German Sport University Cologne, Cologne, Germany \\ Email: f.steinberg@dshs-koeln.de
}

Received August $5^{\text {th }}, 2013$; revised September $4^{\text {th }}, 2013$; accepted October $5^{\text {th }}, 2013$

Copyright $(2) 2013$ Fabian Steinberg et al. This is an open access article distributed under the Creative Commons Attribution License, which permits unrestricted use, distribution, and reproduction in any medium, provided the original work is properly cited.

\begin{abstract}
Word primes have been successfully used in the past to facilitate the processing of other words (semantic priming), but also to modify mental states such as emotion, cognition and motivation (conceptual priming). This work documented that the direction of motivational drive can be successfully changed, but left open whether its magnitude can be influenced as well. To find out, we asked subjects to point at subliminally presented $(30 \mathrm{~ms})$ words that denoted low motivation (13 subjects) or high motivation (13 subjects). Afterwards, subjects completed a questionnaire of learning-specific motivation. No effect of priming was found for pointing parameters such as reaction time, but an effect emerged for self-assessed motivation level. The subject group primed with high-motivation words rated their motivation higher than the group primed with low-motivation words. The results indicate that not only the direction, but also the level of motivation can be manipulated subliminally, and supports the view that motivation can influence behavior without actor's explicit knowledge.
\end{abstract}

Keywords: Semantic Priming; Subliminal Priming; Motivation; Conceptual Priming

\section{Introduction}

Since the influential work of Meyer and Schvaneveldt (1971), it is known that subliminally presented words can facilitate the processing of subsequent, semantically related words. This socalled "semantic priming" has been attributed to spreading activation in brain circuits that store semantically similar words in neighboring locations (Collins \& Loftus, 1975): prime words activate an extended region within those circuits and thus facilitate the processing of subsequent target words (Kiesel, Kunde, \& Hoffmann, 2007). While semantic priming is a robust phenomenon, it also is limited in duration to less than 100 ms (Greenwald, Draine, \& Abrams, 1996).

Semantic priming is distinct from another phenomenon called "conceptual priming": Presented words not only influence the processing of other words, they also can change the reader's attitudes and cognitive styles. For example, words with a hostile connotation biased subjects' ratings of other persons' personality towards more hostile scores (Smith \& Branscombe, 1988), words expressing distrust increased subjects' creativity (Mayer \& Mussweiler, 2011) and words denoting narrowness or wideness narrowed or widened, respectively, subjects' focus of attention (Hüttermann, Memmert, \& Bock, 2012). Conceptual priming doesn't require awareness as it was found with subliminally presented targets (Hüttermann et al., 2012) and in completely amnestic patients (Levy, Stark, \& Squire, 2004). More importantly, the prime words remained effective even after a pause as long as one week. Unlike semantic priming, conceptual priming can therefore be administered in a blocked design, with one block dedicated to the presentation of prime words, and a later block to the measurement of the outcome.

The present study evaluates whether conceptual priming can be used to modify a person's level of motivation. This could be of practical interest, e.g., when a teacher wants to elevate her students' eagerness to learn, or a health consultant wants her clients not only to make plans for a healthy lifestyle, but also to put those plans into action. However, a survey of available literature shows that, surprisingly, conceptual priming has only been used to redirect the motivational drive, not to change its magnitude. Thus, subjects' motivation has been successfully shifted towards either achievement or joy (Hart \& Albaraccin, 2009), either controlled or autonomous self-determination (Radel, Sarrazin, Legrain, \& Gobancé, 2009), and either a promotion or a prevention focus (Steinberg \& Bock, under review). This could indicate that contextual priming of the motivation level has not yet been considered by scientists or, alternatively, that it has been considered but failed to produce statistically significant, publishable effects. Our study was designed to decide between these alternatives.

\section{Method}

\section{Preliminary Procedure: Word Selection}

30 native German speakers ( 23 male, 7 female, $21.1 \pm 2.1$ years) participated. They were university students, healthy by self-report, and unfamiliar with related research. Subjects were given a list of 90 words, selected by the experimenters from a Thesaurus with the aim that 45 words represent a high and 45 words a low motivation level. The high-motivation words were taken from the categories power, energy, strength, activity and hope, and the low-motivation words from the categories weakness, inactivity, dullness and hopelessness.

Participants were asked to rate the motivation level invoked by those words on a ten-point Likert scale, arranged from "low" 
to "high" in one half of the participants and in reverse order for the other half. Upon arrival in the laboratory, they received written instructions that included a definition of "motivation" (Rushworth \& Behrens, 2008), and were told that-as an example-the word "fiasco" should receive a low-motivation score ( 1 or 10 , depending on group). They then were given a sheet of paper on which the 90 words were written in random sequence, and made their ratings.

We determined the inter-rater consistency from the variance accounted for by a one-factor analysis of the ratings, and yielded a value of .66 . Thus, $66 \%$ of the rating variance can be attributed to differences between words, and 34\% to differences between raters as well as to noise. We were satisfied with this outcome, and selected eleven words with the highest and eleven words with the lowest across-rater scores for our main experiment. Those words are presented in Appendix A.

\section{Main Experiment}

\section{Participants}

32 university students took part in the main experiment but only 26 could be analyzed, for reasons given below. Those were 11 males and 15 females, aged $23.6 \pm 2.9$ years. All were native German speakers, healthy by self-report, and have not participated in related research within the last six months. An ethical approval was given by the university's ethical review board, and written informed consent was obtained from each subject prior to participation. Subjects received a compensation of six Euros for participating.

\section{Procedure}

Subjects first completed the Mindfullness Attention Awareness Scale (MAAS) (Michalak, Heidenreich, Ströhle, \& Nachtigall, 2008) to control for the fact that people with low MAAS scores are more sensitive to subliminal priming than people with high MAAS scores (Radel et al., 2009).

Participants were then seated at a distance of $80 \mathrm{~cm}$ in front of a 19" PC monitor. A central hair cross was presented on the screen, followed by a circular target of $4.6 \mathrm{~cm}$ diameter, and subjects pointed from the center to the target and back with a mouse-driven cursor. Targets were presented randomly in 8 possible directions, $45 \mathrm{deg}$ apart with a distance from the hair cross between 8 and $12 \mathrm{~cm}$. As shown in Figure 1, they consisted of a random-dot pattern for the initial $600 \mathrm{~ms}$, followed by a prime word for $30 \mathrm{~ms}$, and then again by the random-dot pattern until the cursor returned to the center. In this way, we sought to refresh the priming effect in every trial, at a time when the cursor, and probably also subjects' gaze and attention, were likely to be near the target. Subject reported retrospectively that they didn't see any words, and only noticed flashes of light.

The next target appeared $30 \mathrm{~ms}$ after the cursor returned to the center, until a total of 24 pointing trials were completed. The first trial was removed from analysis due to a programming error. Participants were randomly assigned to two groups, one primed with words from the high-motivation list and the other with words from the low-motivation list. The primes presented on successive trials were randomly selected from the respective list.

Following the pointing task, subjects received written instructions for the "Tower of Hanoi" game, where five discs must be transferred from one to another of three rods by only moving the upper disc of any rod onto any other rod, and never placing it on top of a smaller disc. After reading the instructions, subjects completed a paper-and-pencil questionnaire of learning-specific motivation (QCM) (Rheinberg, Vollmeyer, \& Burns, 2001). This questionnaire consists of 18 items to be rated on a 7-point Likert scale, such as "I need no reward for tasks like this, they are fun anyways". The experiment terminated with the QCM questionnaire, i.e., subjects didn't actually engage in the "Tower of Hanoi" game.

\section{Data Analysis}

Six subjects were familiar with the "Tower of Hanoi" task and were therefore excluded from all analyses. Reported data are based on the remaining 26 subjects.

Each pointing response was parameterized by an interactive computer routine to yield scores for reaction time, peak velocity and detour, with detour defined as the ratio of actual and shortest distance from movement start to movement end. Student $\mathrm{t}$-tests for independent means were used to compare each motor parameter between groups. MAAS and QCM scores were compared between groups by the non-parametric Mann-Whitney-U tests.

\section{Results}

MAAS scores didn't differ between groups $(\mathrm{z}(24)=-.522 ; p$ $>.05)$, nor did reaction time $(\mathrm{t}(24)=.04 ; p>.05)$, peak velocity $(\mathrm{t}(24)=1.41 ; p>.05)$ and detour $(\mathrm{t}(24)=.73 ; \mathrm{p}>.05)$. We thus have no evidence that our high- and low-motivation groups differed with respect to priming susceptibility or motor dexterity. To control for gradual response changes, regression analyses were performed for the pointing responses of each group. In the high-motivation group, reaction time $\left(\mathrm{R}^{2}=.12 ; \mathrm{F}(1(22)=\right.$ $2.99 ; \mathrm{p}>.05)$, peak velocity $\left(\mathrm{R}^{2}=.11 ; \mathrm{F}(1(22)=2.67 ; p>.05)\right.$ and detour $\left(\mathrm{R}^{2}=.01 ; \mathrm{F}(1(22)=.20 ; p>.05)\right.$ didn't change over time. Likewise in the low-motivation group reaction time $\left(\mathrm{R}^{2}\right.$ $=.003 ; \mathrm{F}(1(22)=.05 ; p>.05)$, peak velocity $\left(\mathrm{R}^{2}=.02\right.$;

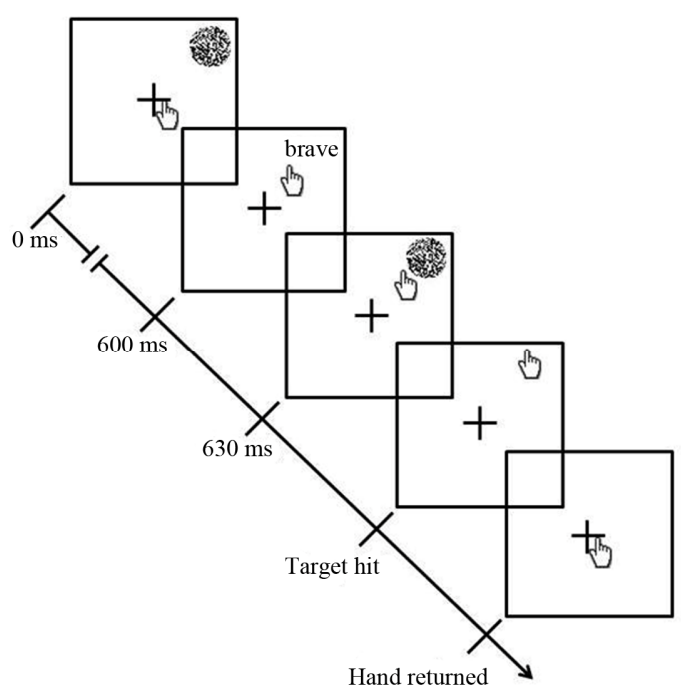

Figure 1.

Sequence of events during target presentation. Shown is the hand starting position (central hair cross), the mouse cursor (hand icon) the target (random dots) and a prime word. When target hit and cursor back at hair cross, the next trial starts. 
$\mathrm{F}(1(22)=.58 ; p>.05)$ and detour $\left(\mathrm{R}^{2}=.07 ; \mathrm{F}(1(22)=.32 ; p\right.$ $>$.05) didn't change over time.

However, QCM scores differed substantially between groups $(z(24)=-2.90 ; p<.01)$. Figure 2 illustrates that self-assessed motivation to engage in the "Tower of Hanoi" game was higher in subjects primed with high-motivation words than in those primed with low-motivation words.

\section{Discussion}

We evaluated whether conceptual priming of the motivation level is a neglected research topic, or rather failed to produce significance and thus suffered the "file-drawer effect". To find out, words denoting a high or a low motivation level were subliminally presented during a manual-pointing task, and subjects were subsequently questioned about their motivation to engage in a cognitively demanding task, the "Tower of Hanoi" game. Our data document higher QCM scores for subjects primed for high rather than for low motivation, from which we conclude that our priming procedure was successful. In other words, contextual priming can effectively modify not only the direction (Radel et al., 2009; Steinberg \& Bock, under review), but also the magnitude of the motivational drive. Since the primes were forward and backward masked and were presented for only 30 $\mathrm{ms}$, they could not be consciously perceived; indeed subjects reported retrospectively that they had been unaware of them. Our data therefore contradict the view that motivation is a purely conscious process (Weiner, 1992), and rather support the alternative notion that motivation can influence behavior without the actor's explicit knowledge (Custers \& Aarts, 2010 motivation can escape awareness).

It is interesting to note that contextual priming changed subjects' attitude towards the "Tower of Hanoi" game, but didn't reliably modify their performance in the pointing task. One possible explanation is that the motivation level changed gradually, such that a substantial change was only achieved by the end of the pointing task. However, regression analysis of pointing parameters does not support this assumption. The other, more likely explanation is that the pointing was stereotyped, automated, unrewarded and thus was insensitive to the subjects' level of motivation.

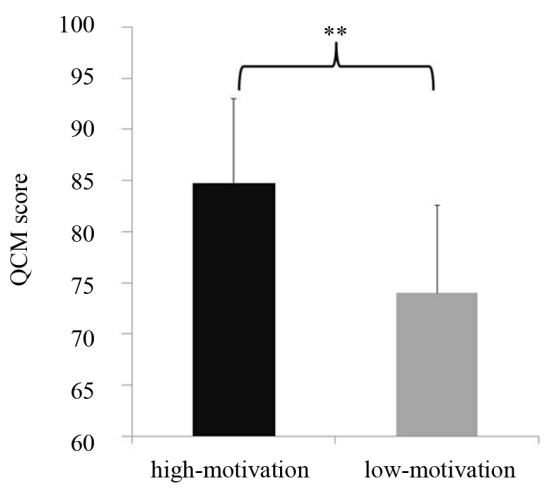

Figure 2.

QCM scores for subjects primed with high- and with low-motivation words, respectively. Blocks represent group means and error bars the pertinent standard deviations. ${ }^{* *}$ represents $p<.01$.

\section{Acknowledgements}

Thanks are due to Judith Horch for data analysis and Marlon Drescher for technical support and software development. This work was supported by a Grant from the German Ministry for Economy and Technology, administered through the German Space Agency DLR (50WB1224).

\section{REFERENCES}

Collins, A. M., \& Loftus, E. F. (1975). A spreading-activation theory of semantic processing. Psychological Review, 82, 407-428. http://dx.doi.org/10.1037/0033-295X.82.6.407

Custers, R., \& Aarts, H. (2010). The unconscious will: How the pursuit of goals operates outside of conscious awareness. Science, 329, 4750. http://dx.doi.org/10.1126/science.1188595

Greenwald, A. G., Draine, S. C., \& Abrams, R. L. (1996). Three cognitive markers of unconscious semantic activation. Science, 273, 1699 1702. http://dx.doi.org/10.1126/science.273.5282.1699

Hart, W., \& Albaraccin, D. (2009). The effects of chronic achievement motivation and achievement primes on the activation of achievement and fun goals. Journal of Personality and Social Psychology, 97, 1129-1141. http://dx.doi.org/10.1037/a0017146

Hüttermann, S., Memmert, D., \& Bock, O. (2012). Semantic priming of attention focus: Evidence for short-and long-term effects. Psychology, 3, 128-131. http://dx.doi.org/10.4236/psych.2012.32019

Kiesel, A., Kunde, W., \& Hoffmann, J. (2007). Mechanisms of subliminal response priming. Advances in Cognitive Psychology, 3, 307-315. http://dx.doi.org/10.2478/v10053-008-0032-1

Levy, D. A., Stark, C. E. L., \& Squire, L. R. (2004). Intact conceptual priming in the absence of declarative memory. Psychological Science, 15, 680-686. http://dx.doi.org/10.1111/j.0956-7976.2004.00740.x

Mayer, J., \& Mussweiler, T. (2011). Suspicious spirits, flexible minds: When distrust enhances creativity. Journal of Personality and Social Psychology, 101, 1262-1277. http://dx.doi.org/10.1037/a0024407

Meyer, D., \& Schvaneveldt, R. (1971). Facilitation in recognizing pairs of words: Evidence of a dependence between retrieval operations. Journal of Experimental Psychology, 90, 227-234. http://dx.doi.org/10.1037/h0031564

Michalak, J., Heidenreich, T., Ströhle, G., \& Nachtigall, C. (2008). Die deutsche Version der Mindful Attention and Awareness Scale (MAAS) Psychometrische Befunde zu einem Achtsamkeitsfragebogen. Zeitschrift für Klinische Psychologie und Psychotherapie, 37, 200-208. http://dx.doi.org/10.1026/1616-3443.37.3.200

Radel, R., Sarrazin, P., Legrain, P., \& Gobancé, L. (2009). Subliminal priming of motivational orientation in educational settings: Effect on academic performance moderated by mindfulness. Journal of Research in Personality, 43, 695-698. http://dx.doi.org/10.1016/j.jrp.2009.02.011

Rheinberg, F., Vollmeyer, R., \& Burns, B. D. (2001). FAM: Ein Fragebogen zur Erfassung aktueller Motivation in Lern-und leistungssituationen. Diagnostica, 47, 57-66.

http://dx.doi.org/10.1026//0012-1924.47.2.57

Rushworth, M. F. S., \& Behrens, T. E. J. (2008). Choice, uncertainty and value in prefrontal and cingulate cortex. Nature Neuroscience, 11, 389-397. http://dx.doi.org/10.1038/nn2066

Smith, E. R., \& Branscombe, N. R. (1988). Category accessibility as implicit memory. Journal of Experimental Social Psychology, 24, 490-504. http://dx.doi.org/10.1016/0022-1031(88)90048-0

Steinberg, F., \& Bock, O. (under review). Differential effects of motivation on grasping.

Weiner, B. (1992). Human motivation: Metaphors, theories, and research (2 ed.). London: Sage. 


\section{Appendix A}

\section{High-Motivation Words:}

exzellent [excellent]; kraftvoll [vigorous]; wirksam [efficient]; mutig [brave]; lebhaft [vivid]; können [ability]; aussichtsreich [promising]; unwiderstehlich [irresistible]; machtvoll [powerful]; enthusiastisch [enthusiastic]; effektiv [effective].

\section{Low-Motivation Words:}

Schwach [weak]; sinnlos [meaningless]; schlaff [slack]; ineffektiv [ineffective]; geschmachklos [crude]; wertlos [worthless]; absturz [crash]; hilflos [helpless]; lustlos [dull]; unrentabel [unprofitable]; gezwungen [forced]. 